\title{
Application of external prestressing on the rehabilitation of reinforced concrete beams
}

\author{
Ali K. AL-Asadi \\ University of Sumer, Rifai, Iraq.
}

\begin{abstract}
Article Info
Received Jan 15, 2019

\section{Keyword:}

Prestressing

Reinforced Concrete (RC)

Rehabilitation

Beams

Loading

Stress

Deflection

ABSTRACT

Concrete structure experiencing any form of distress due to multiple reasons; need remedial, strengthening, and rehabilitation measures, if the structure is to attain serviceability and strength requirements of different elements. Further, the external welding reinforcement and prestressing of the reinforced concrete members have been proven to provide an effective strengthening approach. The prestressed concrete describes a type of concrete where internal stresses are instituted to counteract the multiple tensile stresses that are characteristics of service loading. In these concrete structures, cables, hard-drawn wires or bars of high strength alloy steel are employed as tendons to generate the counteracting stresses. The prestressed concrete is made up of an active combination of steel and concrete as these materials are traditionally stressed before the application of external loads. The prestressing technique has been comprehensively reviewed in numerous articles showing that it is more effective than the RCC structures. External prestressing is emerging as an essential component of prestressing as it is structurally attractive and economical. In external prestressing, the tendons are placed outside the member to improve the load-bearing capacity of the structures and their members. In this study, a beam exposed to various loading condition and distress is strengthened using external prestressing. The ultimate deflection and failure characteristics were evaluated using different loading scenarios; beam weight, live weight, and dead weight. The results for the prestressing analysis was provided for 10 and 20 strands.
\end{abstract}

\section{Corresponding Author:}

Ali K. AL-Asadi

University of Sumer,

Rifai, Thi-Qar, Iraq

Email: alazharco.2005@yahoo.com

\section{Introduction}

The external prestressing technique has been widely employed in the construction of urban, railway, and highway bridges [1]. In design and construction, the fundamental theory and formulas are used in the determination of the prestressing force. Durability elements such as shrinkage, temperature, and creep have been found to cause many changes in the prestressing force. Recently, there has been a surge in need for strengthened reinforced bridges due to the increase in the traffic loads, corrosion of steel reinforcement, and progressive structural aging [2]. External prestressing has been identified as a relatively new technique of strengthening these structures due to its speed and possibility of monitoring, replacing, and future tensioning of the tendons. External prestressing was initially used for strengthening of bridges, but it has since been utilized in the building of new structures and other strengthening needs [3]. Additionally, it has become a prevalent approach for external prestressing of concrete structures as it enhances the load-bearing capacity of a structural member. Steel, concrete, and timber have been utilized for external prestressing with steel and 
fiber-reinforced polymer (FRP) being the most commonly used material for external prestressing [4]. In external prestressing the load is actively inducted by tendons imposing the stress on the concrete; thus, the behavior remains predominantly flexural. The external prestressing method has introduced an efficient solution for improving the rating capacity of existing bridges during the renewal of the infrastructure [5]. Furthermore, the use of external prestressing in the rehabilitation of structures as demonstrated an increase in life expectancy of the system and the individual member while simultaneously increasing the flexural strength significantly, thus reducing deflection and cracks widths.

Prestressing as a technique has been applied for stresses in the structural member whose values are known prior to the application of a full or live load [2]. The prestressed concrete describes reinforced concrete (RC) where the steel used for reinforcement is tensioned against the concrete. The stresses in these concrete structures are induced by the tensioning of the high tensile rods, strands, or wires which are completely anchored to the members that are under prestressing wire mechanical means [3]. Thus, in prestressing allowed applied to the prestressed reinforced concrete member containing bonded tendons causing equal strains on both adjacent tendon and the concrete. The compatibility of the concrete and tendon strains is a fundamental assumption in the computation for the strain and stress in prestressed sections [6]. The prestressing technique is vital for functionality and the stability of structures as it simplifies the connection and enhances the performance through limiting cracking and increasing stiffness. Prestressing can be applied in the following three areas, 1) In structural members with a greater length characterized by low rise and low structural height, 2) In building structures to attain lighter beams and slabs therefore considerably decreasing the dead load as compared to the RCC structures and 3) In Mega structures like in LNG storage Tanks, Dams, Containment walls in nuclear reactors, Chimneys, Rock Anchors and Cement Silos.

\section{External prestressing}

External prestressing defines post-tensioning technique where the tendons are placed outside the structure member [3]. This approach has been widely applied in the strengthening of bridges and buildings. The technique is attractive, especially in strengthening activities as it adds little weight to the initial structure making it easy to monitor, retrace, and replace tendons [2]. The technique is effective in both new and existing structures with the following advantages

1. Monitoring the profile of external tendons is easy both during and after installation, enhancing the inspection process.

2. Removal and replacement of external tendons during maintenance

3. Grouting is enhanced due to proper visualization

4. The technique reduces the dead load as the members can be made thinner.

In this research, we evaluate the applicability of external prestressing on rehabilitating reinforced concrete beams. The rehabilitation of the concrete beams is vital in the replacement and strengthening of structural members in construction. A comprehensive literature review was carried out to effectively provide a background on the emergence and use of external prestressing in strengthening structural members. Then a proposed approach is used for evaluation of prestressing and how it can be employed as a reliable and economical technique for rehabilitation of RC beams.

\section{Literature Review}

Demir et al. devised an alternative technique for straightening reinforced concrete beams using external steel members [1]. In this study, Demir et al., employed external steel members to improve both Shia and flexural capacities of the reinforced concrete beams (RC). The research considered two types of RC beams, i.e., ones without stirrups and those lacking the stirrups [1]. The beams were strengthened externally using steel clamps external longitudinal reinforcements. The use of steel clamps did not impact the load-bearing potential significantly of the test beams [1]. The ductility of the test beams increased significantly, and the failure characteristic changed from brittle to ductile. It was evident that the application of the clamps and longitudinal reinforcement did not considerably impact the ductility of test beams but increased the load capacities. Our research extends the analysis to create the viability of prestressing in rehabilitating RC beams.

Muthukumar et al. reports on an analytical and experimental study evaluating the use of the external prestressing technique in strengthening and rehabilitating distress RC beams. The beams in the experiment 
were subjected to various degrees of distress and then strengthened using multiple levels of prestressing. The prestressed RC beams were tested for destruction [3]. The performance testing in this research investigated the beams with regards to stiffness characteristics, first crack load, failure load, crack propagation, ductility, failure mode, and the ultimate deflection. It was discovered that the trussed beam experienced delayed the first crack with improved stiffness characteristic [3]. The prestressing of the tie rod also improved the load-bearing capacity as well as stiffness features. Moreover, the load-bearing capacity of the rehabilitated beam was expanded considerably compared to the original RC beam [7]. This research dwelt on existing structures, whereas in our case, we evaluate the possibility of rehabilitating RC beams using external prestressing.

Ibrahim et al. investigated the parameters required for continuous concrete beam prestressed with external tendons. In this evaluation, he analyzes the behavior of members a different ultimate limit state. He used the ANSYS 10 computer program for dimensional finite element analysis of the model developed [8]. In comparing the flexural behavior at the ultimate capacity consider the following parameters; initial prestressing stress, concrete strength, loading arrangement, the resulting depth of the external filaments and the tendon profiles [8]. In this exercise, the final load capacity was improved as the comprehensive strength of the concrete increased. The results concluded that the surge in the effective strength led to the increase in the ultimate load effective prestressing [8]. The case of tendon profile demonstrated that the final load increased for the selected structure with different draped tendons when compared to the draped tendon profiles [9]. This analysis utilized finite element to analyze the parameters of continual concrete beam prestressed with external ligament while our research utilized the ConsiceBeam software investigate the effectiveness of external prestressing in rehabilitating $\mathrm{RC}$ beams.

Xue et al. acknowledge that the shear performance of a concrete beam is a vital mechanical feature; therefore, improved fear resistance is an essential component in the determination of a beams performance and its longevity [4]. This study evaluated the shear performance of concrete beams without web reinforcement by strengthening using external vertical prestressing rebars (EVPRs). Seven test beams were used for the collection of experimental data to characterize the factors influencing the shear behavior of concrete beams, i.e., stirrup ratio, comprehensive stress degree, arrangement spacing and prestressing force [4]. The results in this study showed that EVPRs substantially enhance the shear potentiality and ductility of concrete beams without the need for web reinforcement [10]. Additionally, the failure mode of these concrete beams changes from brittle diagonal tension tour mildly ductile shear compression. The shear and flexural cracks are entirely developed in these beams. The shear performance of the concrete beams become profound as the compressive stress degree and stirrup ratio are increased; the vertical compressive stress generated by the EVPRs would decrease the fundamental tensile stress of the concrete thus preventing share cracking while enhancing shear tolerance of the concrete structure [4]. The EVPRs can be utilized in the initial stages of the construction of the critical shear crack (CSC) to create stirrups during shear failure by sharing the shear load [7]. The research concludes that EVPR effectively improves the shear performance of concrete beams. This research dwells on the effect of EVPR on shear performance while ignoring the impact of external prestressing on the strengthening of RC beams. Our research will characterize the impact of external prestressing on RC beams providing the performance under ultimate deflection.

Yue-lin et al. studied the strengthening of RC beams utilizing prestressed glass fiber-reinforced polymer (PGFRP). The carbon fiber-reinforced polymer (CFRP) has gained popularity for employment in the repair of restoration material for the deteriorated RC structures [5]. The CFRP material is very stiff thus the distinction between the properties of the CFRP sheets and concrete will not favor the transfer of prestressing from the CFRP sheets to RC structure components [11]. Glass fiber-reinforcement polymer (GFRP) sheets have an elasticity Modulus that is close to that of concrete that is why it was selected in the study. In this study, Yuelin et al. tested the deflection and the load-bearing capacity of the strengthened RC beams using the PGFRP and GFRP. The T-and Inverted-T shaped beams employed as the under-strengthened and over-strengthened beams. The GFRP sheets in the experiment were prestressed to one-half of their tensile potentiality prior to bonding with the T-and Inverted-T shaped RC beams [5]. The results illustrated that the prestressed tension in the PGFRP led to the cambers in the RC beams without the cracks in the tensile faces [5]. The PGFRP sheets significantly improved the load-carrying capacity. Similarly, the T-shaped beams combined with the GFRP sheet enhances the load-carrying capacity. Under external loads, the GFRP experienced a more significant deflection than the PGFRP [5]. This research utilizes glass in reinforcing the concrete beams, but in our study, we utilize steel strands for external prestressing to rehabilitate RC beams. 


\section{The proposed system}

This research applies the external prestressing to rehabilitate $\mathrm{RC}$ beams. The proposed system utilized Concise Beam 4.62i to simulate the various loading scenarios of the prestressed RC beams that are being rehabilitated. This system would accomplish a comprehensive evaluation of the effect of the tendons on the rehabilitation of the prestressed RC beams on shear capacity and crack distribution giving a detailed behavior of external prestressed RC beam. This process will seek to satisfy the following requirements;

The vertical components of the external prestressing resist shear force in the structural member.

The prestressing will flatten the inclination of the shear crack, therefore, enhancing the impact of the stirrups.

The external prestressing increases the degree of shear compression zone thus improving the shear contribution of the concrete.

The prestressing of the diagonal shear crack is delayed; therefore, the propagation of the critical shear crack would be restrained by the prestressing, resulting in a relatively large shear crack load and shear strength.

The results of the research will be determined using the following shear strength formula. The formula would characterize the tendon distribution.

Where

$$
V_{u}=K\left(V_{c}+V_{s}\right)+V_{p}
$$

$K$ is the increasing coefficient of the external prestressing given by $\sqrt{\frac{f p c}{f t}}+1$

$V_{p}$ is the external tendon shear contribution

Material Properties

The concrete strength is a significant parameter for the evaluation of the external prestressing used in the rehabilitation of the RC beams as it will affect the results in the simulation, especially in shear strength. Table 1 below illustrates the features of the concrete used in the numerical analysis.

Table 1. The properties of the concrete material used in the simulation.

\begin{tabular}{|l|l|}
\hline Precast Beam & Value \\
\hline Parameter & 2400 \\
\hline Density (kgm3) & 40 \\
\hline Compressive strength (MPa) & 29602 \\
\hline Modulus of Elasticity (MPa) & Value \\
\hline Cast-in-Place Pour \\
\hline Parameter \\
\hline Density (kgm3) & 2400 \\
\hline Compressive strength (MPa) & 30 \\
\hline Modulus of Elasticity (MPa) & 26621 \\
\hline Prestressed beam at Transfer \\
\hline Parameters & Value \\
\hline Compressive strength (MPa) & 28 \\
\hline Modulus of Elasticity (MPa) & 25968 \\
\hline During Initial Lifting & Value \\
\hline Parameters & 30 \\
\hline Compressive strength (MPa) & 26621 \\
\hline Modulus of Elasticity (MPa) &
\end{tabular}

The experimental specimens consisted of different strands. The first scenario the prestressed concrete was made of ten strands and twenty for the second. Figure 1a demonstrates the cross-section of the specimen below and while figure $1 \mathrm{~b}$ shows the length of the specimen that was selected for the deflection analysis.

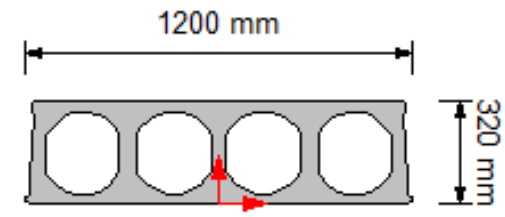

Figure 1a. The cross-section of the specimen used for the simulation 


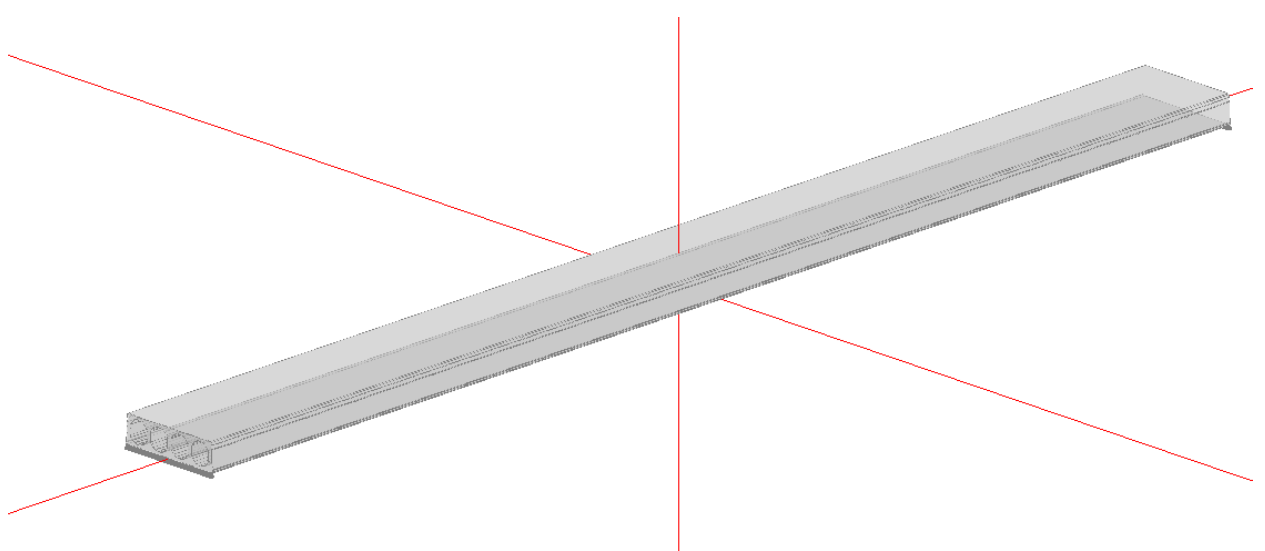

Figure $1 \mathrm{~b}$. The length of the specimen used for the simulation

The section properties for the specimen selected in the experiment is illustrated in table 2 . The parameters will define the loading behavior of the specimen.

Table 2: The parameters for the loading of the concrete

\begin{tabular}{|l|l|}
\hline Parameters & Value \\
\hline Cross-Sectional Areas, A & $178514 \mathrm{~mm} 3$ \\
\hline Moment of Inertia, I & $2373268012 \mathrm{~mm} 4$ \\
\hline Height of the Centroid, yb & $158 \mathrm{~mm}$ \\
\hline Volume to surface Ratio, V/S & $59 \mathrm{~mm}$ \\
\hline Shear Width, bw & $251 \mathrm{~mm}$ \\
\hline Height of Section & $320 \mathrm{~mm}$ \\
\hline Width of section & $1200 \mathrm{~mm}$ \\
\hline
\end{tabular}

\section{Results}

The beam specimen was set up as illustrated in figure $2 a, b, c$ for the various position. The beam will be support at both ends using the frames. The beams will be evaluated for three different scenarios i.e., initial load (FC), dead load (DL) and the Live Load (LL).

F.C [1.50/1.50]

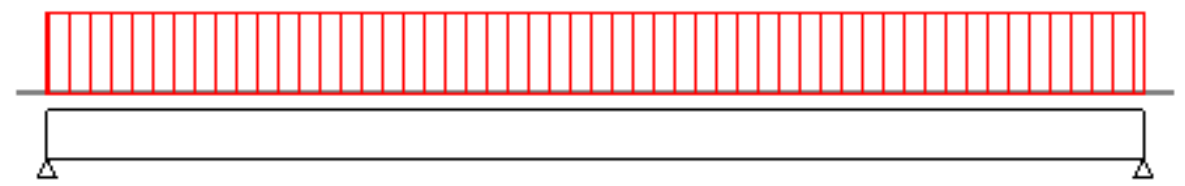

Figure 2a. The initial loading of the system setup for the $1.5 \mathrm{kN}$

\section{D.L $[1.25 / 1.25]$}

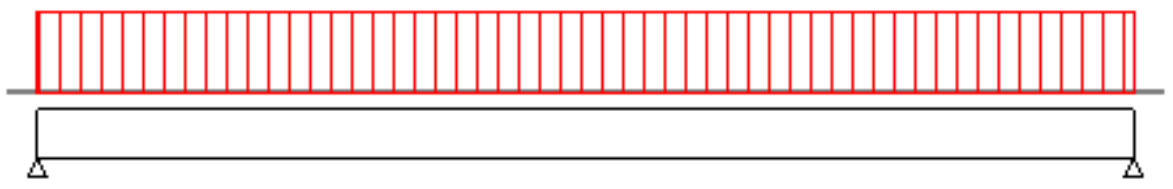

Figure $2 b$. The set up for the dead load for $1.25 \mathrm{kN}$

L.L $[1.00 / 1.00]$

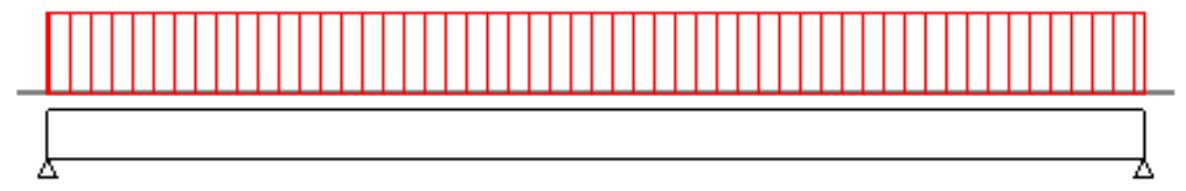

Figure 2c. The set up for the Live load for $1.0 \mathrm{kN}$ 
The loading in figure $2 \mathrm{a}, \mathrm{b}$ and $\mathrm{c}$ show the various loading scenarios that were used to evaluate the rehabilitation ability of external prestressing to rehabilitate the $\mathrm{RC}$ beams $[12,16,17]$. The beam is supported between two-point supports that will ensure the load is applied through the desired points to initiate deflection $[1,18]$. The loading on the beams was evenly distributed to be able to monitor the shear cracking and the deflection of the beams. The result in the simulation was recorded for the deflection.

Table 3. Deflection for 10 Strands in the Beam

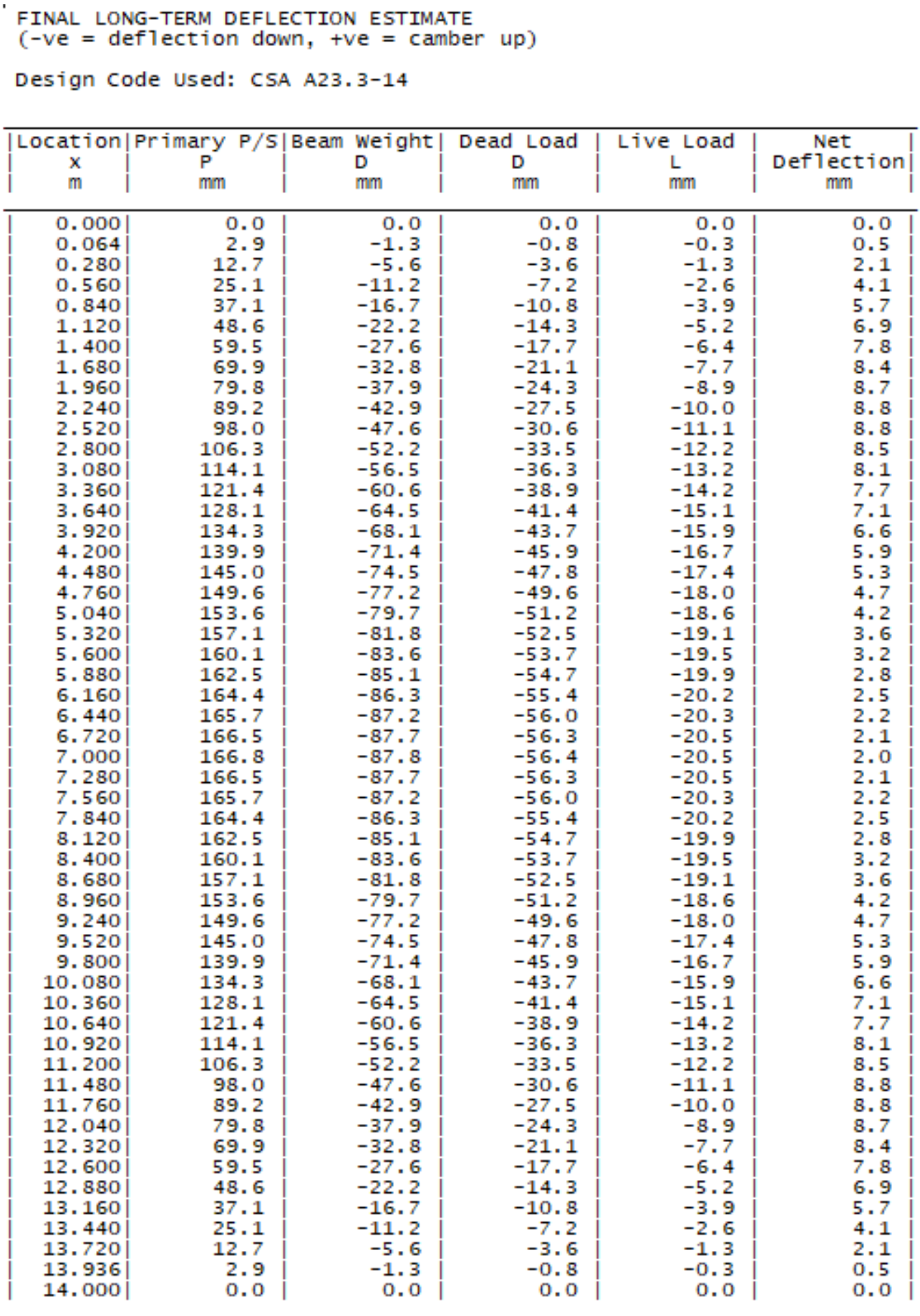

Table 3 above illustrates the ConsiceBeam results for ten strands used for external prestressing to rehabilitate the RC beams [13]. The results illustrate that the greatest deflection of $8.8 \mathrm{~mm}$ was recorded near the end of the bar close to the support. The bulk of the deflection was caused by the weight of the beam, which was considerable [14]. The value for loading is recorded as negative from the normal as it shows the direction against gravity to cause deflection. 
Table 4. Deflection for 20 Strands in the Beam

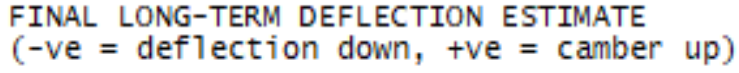

\begin{tabular}{|c|c|c|c|c|c|}
\hline \begin{tabular}{|c|} 
Location \\
$x$ \\
$m$
\end{tabular} & $\mid \begin{array}{c}\text { Primary } P / S \\
\mathrm{P} \\
\mathrm{mm}\end{array}$ & $\begin{array}{c}\text { Dead Load } \\
\mathrm{D} \\
\mathrm{mm}\end{array}$ & $\begin{array}{c}\text { Beam Weight } \\
\text { D } \\
\mathrm{mm}\end{array}$ & $\begin{array}{c}\text { Live Load } \\
\mathrm{L} \\
\mathrm{mm}\end{array}$ & $\begin{array}{c}\text { Net } \\
\text { Deflection } \\
\mathrm{mm}\end{array}$ \\
\hline 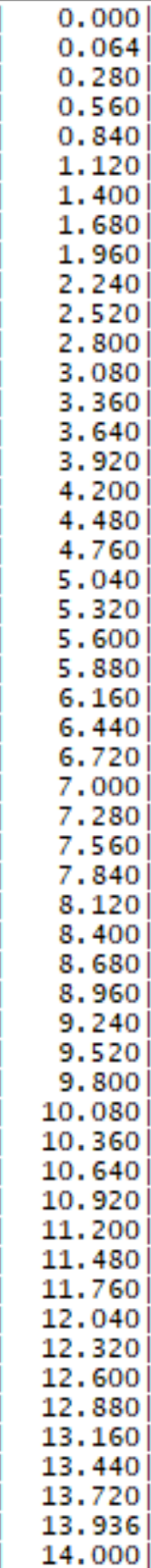 & $\begin{array}{r}0.0 \\
5.4 \\
23.7 \\
46.9 \\
69.1 \\
90.4 \\
110.7 \\
130.0 \\
148.4 \\
165.7 \\
182.1 \\
197.5 \\
211.9 \\
225.3 \\
237.8 \\
249.2 \\
259.7 \\
269.1 \\
277.6 \\
285.1 \\
291.6 \\
297.0 \\
301.5 \\
305.0 \\
307.5 \\
309.0 \\
309.5 \\
309.0 \\
307.5 \\
305.0 \\
301.5 \\
297.0 \\
291.6 \\
285.1 \\
277.6 \\
269.1 \\
259.7 \\
249.2 \\
237.8 \\
225.3 \\
211.9 \\
197.5 \\
182.1 \\
165.7 \\
148.4 \\
130.0 \\
110.7 \\
90.4 \\
69.1 \\
46.9 \\
23.7 \\
5.4 \\
0.0\end{array}$ & $\begin{array}{r}0.0 \\
-0.8 \\
-3.7 \\
-7.3 \\
-10.8 \\
-14.2 \\
-17.5 \\
-20.8 \\
-23.9 \\
-27.0 \\
-29.9 \\
-32.8 \\
-35.4 \\
-38.0 \\
-40.4 \\
-42.6 \\
-44.7 \\
-46.6 \\
-48.3 \\
-49.8 \\
-51.1 \\
-52.2 \\
-53.2 \\
-53.9 \\
-54.4 \\
-54.7 \\
-54.8 \\
-54.7 \\
-54.4 \\
-53.9 \\
-53.2 \\
-52.2 \\
-51.1 \\
-49.8 \\
-48.3 \\
-46.6 \\
-44.7 \\
-42.6 \\
-40.4 \\
-38.0 \\
-35.4 \\
-32.8 \\
-29.9 \\
-27.0 \\
-23.9 \\
-20.8 \\
-17.5 \\
-14.2 \\
-10.8 \\
-7.3 \\
-3.7 \\
-0.8 \\
0.0\end{array}$ & $\begin{array}{r}0.0 \\
-1.3 \\
-5.8 \\
-11.4 \\
-16.8 \\
-22.0 \\
-27.2 \\
-32.2 \\
-37.1 \\
-41.8 \\
-46.4 \\
-50.8 \\
-54.9 \\
-58.9 \\
-62.6 \\
-66.0 \\
-69.2 \\
-72.2 \\
-74.8 \\
-77.2 \\
-79.2 \\
-81.0 \\
-82.4 \\
-83.5 \\
-84.4 \\
-84.8 \\
-85.0 \\
-84.8 \\
-84.4 \\
-83.5 \\
-82.4 \\
-81.0 \\
-79.2 \\
-77.2 \\
-74.8 \\
-72.2 \\
-69.2 \\
-66.0 \\
-62.6 \\
-58.9 \\
-54.9 \\
-50.8 \\
-46.4 \\
-41.8 \\
-37.1 \\
-32.2 \\
-27.2 \\
-22.0 \\
-16.8 \\
-11.4 \\
-5.8 \\
-1.3 \\
0.0\end{array}$ & $\begin{array}{r}0.0 \\
-0.3 \\
-1.3 \\
-2.7 \\
-3.9 \\
-5.2 \\
-6.4 \\
-7.6 \\
-8.7 \\
-9.8 \\
-10.9 \\
-11.9 \\
-12.9 \\
-13.8 \\
-14.7 \\
-15.5 \\
-16.2 \\
-16.9 \\
-17.6 \\
-18.1 \\
-18.6 \\
-19.0 \\
-19.3 \\
-19.6 \\
-19.8 \\
-19.9 \\
-19.9 \\
-19.9 \\
-19.8 \\
-19.6 \\
-19.3 \\
-19.0 \\
-18.6 \\
-18.1 \\
-17.6 \\
-16.9 \\
-16.2 \\
-15.5 \\
-14.7 \\
-13.8 \\
-12.9 \\
-11.9 \\
-10.9 \\
-9.8 \\
-8.7 \\
-7.6 \\
-6.4 \\
-5.2 \\
-3.9 \\
-2.7 \\
-1.3 \\
-0.3 \\
0.0\end{array}$ & $\begin{array}{r}0.0 \\
3.0 \\
12.9 \\
25.5 \\
37.6 \\
49.0 \\
59.6 \\
69.5 \\
78.6 \\
87.1 \\
94.9 \\
102.1 \\
108.7 \\
114.7 \\
120.1 \\
125.1 \\
129.5 \\
133.5 \\
137.0 \\
140.0 \\
142.6 \\
144.8 \\
146.6 \\
148.0 \\
149.0 \\
149.5 \\
149.7 \\
149.5 \\
149.0 \\
148.0 \\
146.6 \\
144.8 \\
142.6 \\
140.0 \\
137.0 \\
133.5 \\
129.5 \\
125.1 \\
120.1 \\
114.7 \\
108.7 \\
102.1 \\
94.9 \\
87.1 \\
78.6 \\
69.5 \\
59.6 \\
49.0 \\
37.6 \\
25.5 \\
12.9 \\
3.0 \\
0.0\end{array}$ \\
\hline
\end{tabular}

Table 4 above illustrates the ConsiceBeam results for 20 strands used for external prestressing to rehabilitate the RC beams $[15,19]$. The results demonstrate that the greatest deflection of $149 \mathrm{~mm}$ was at the center of the bar in between the supports. The depression was caused by the loading as the effect of the loads could be observed easily. 


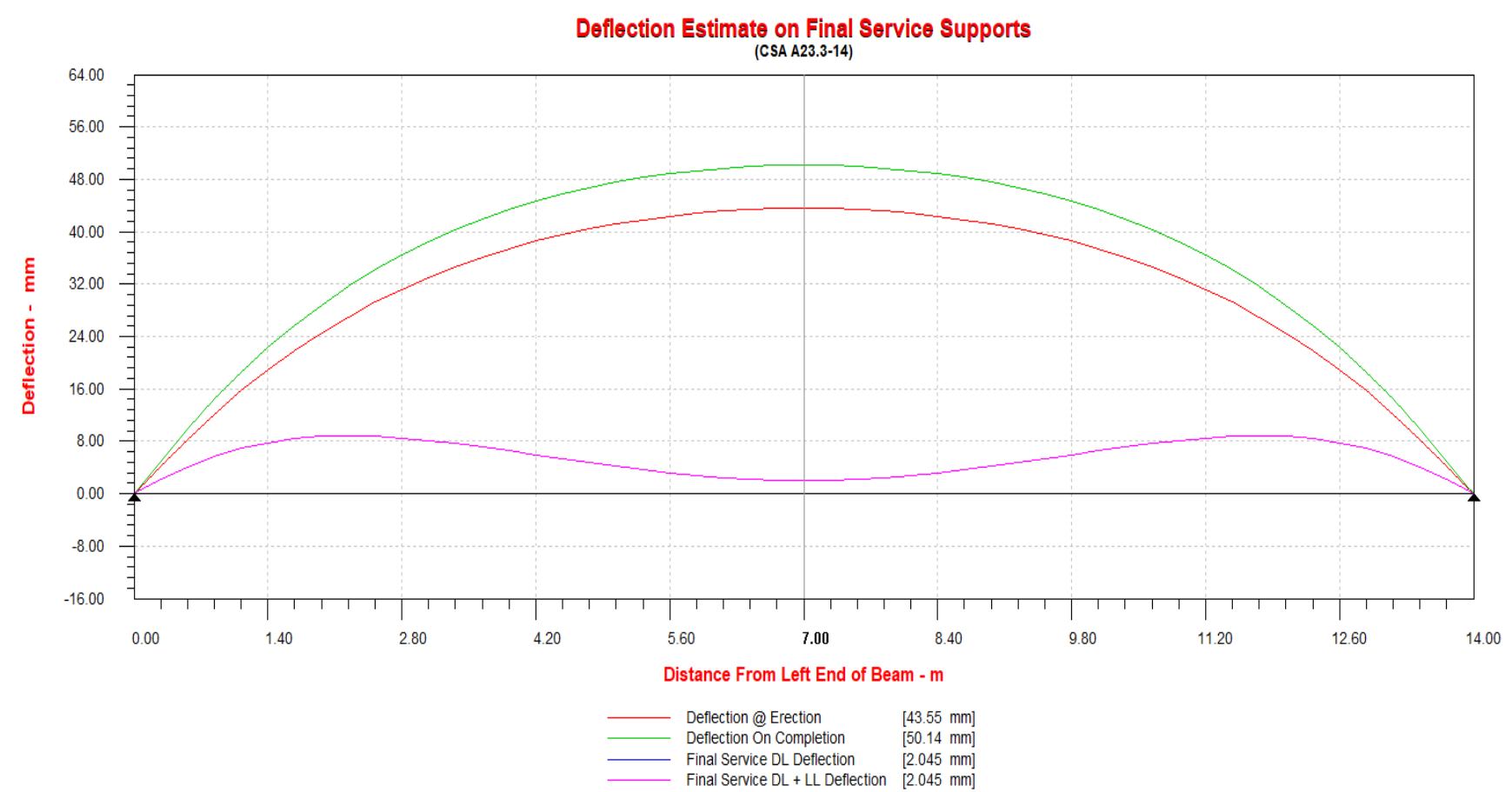

Figure 3. The deflection profile for the ten strands and the limits allowable for the structure member.

The deflection in the specimen with ten strands had a profile outlined in the graph above. The deflection was $8.8 \mathrm{~mm}$ on the two crests, whereas the allowable deflection for the structural member was within the range 43.55-50.14 $\mathrm{mm}$ [15]. It is evident the loading on the member did not significantly affect the properties and the operation of the beam.

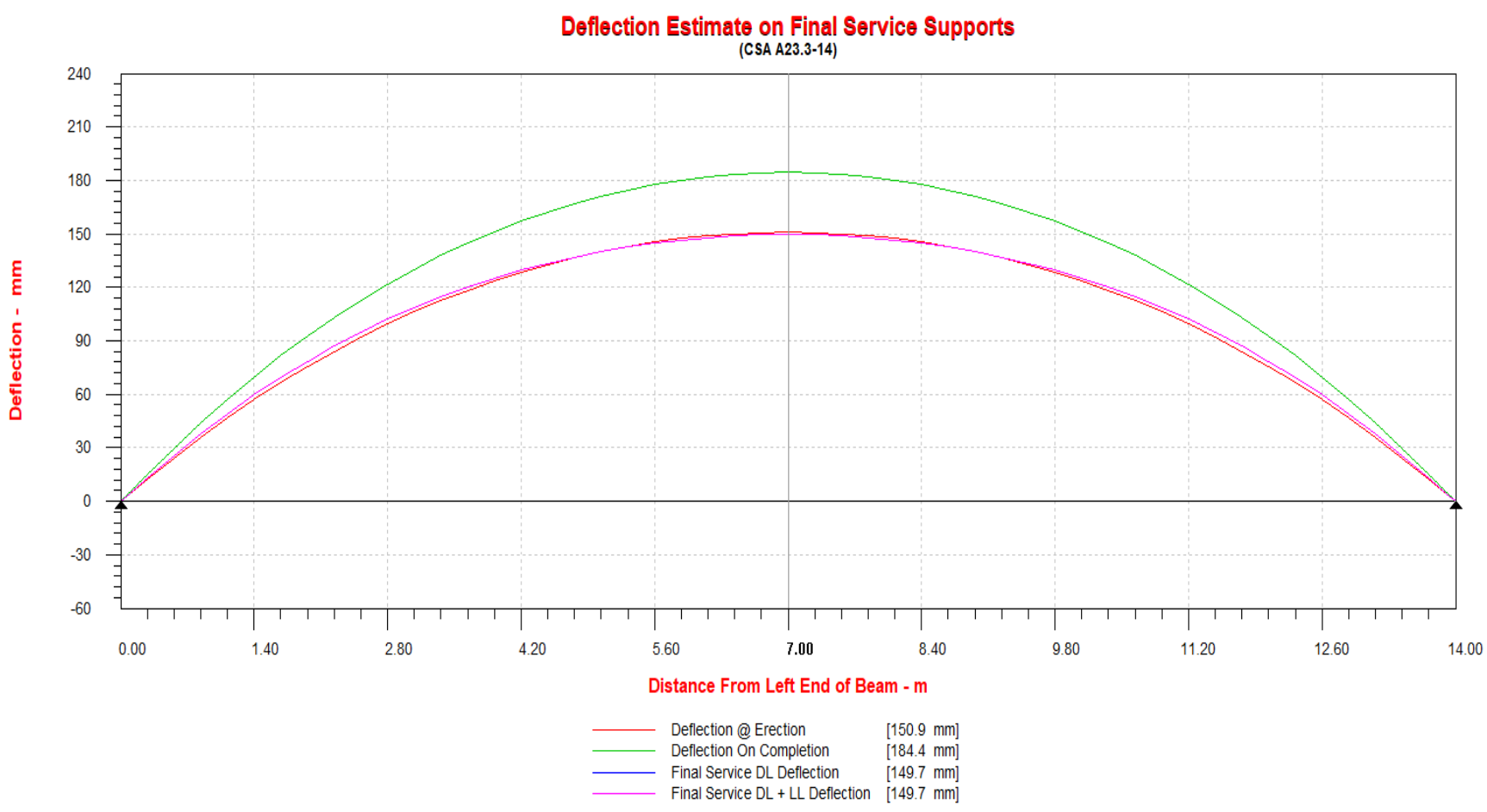

Figure 4: The deflection profile for the 20 strands and the limits allowable for the structure member.

The 20 strand specimen described a deflection formation illustrated in the figure above. The RC beam was considerably deflected at the center [13]. The deflection for this section was $149 \mathrm{~mm}$, which was close to the 
range in the allowable limit of 150.9-184.4 $\mathrm{mm}$. The loading in this scenario led to increased stress on the beam.

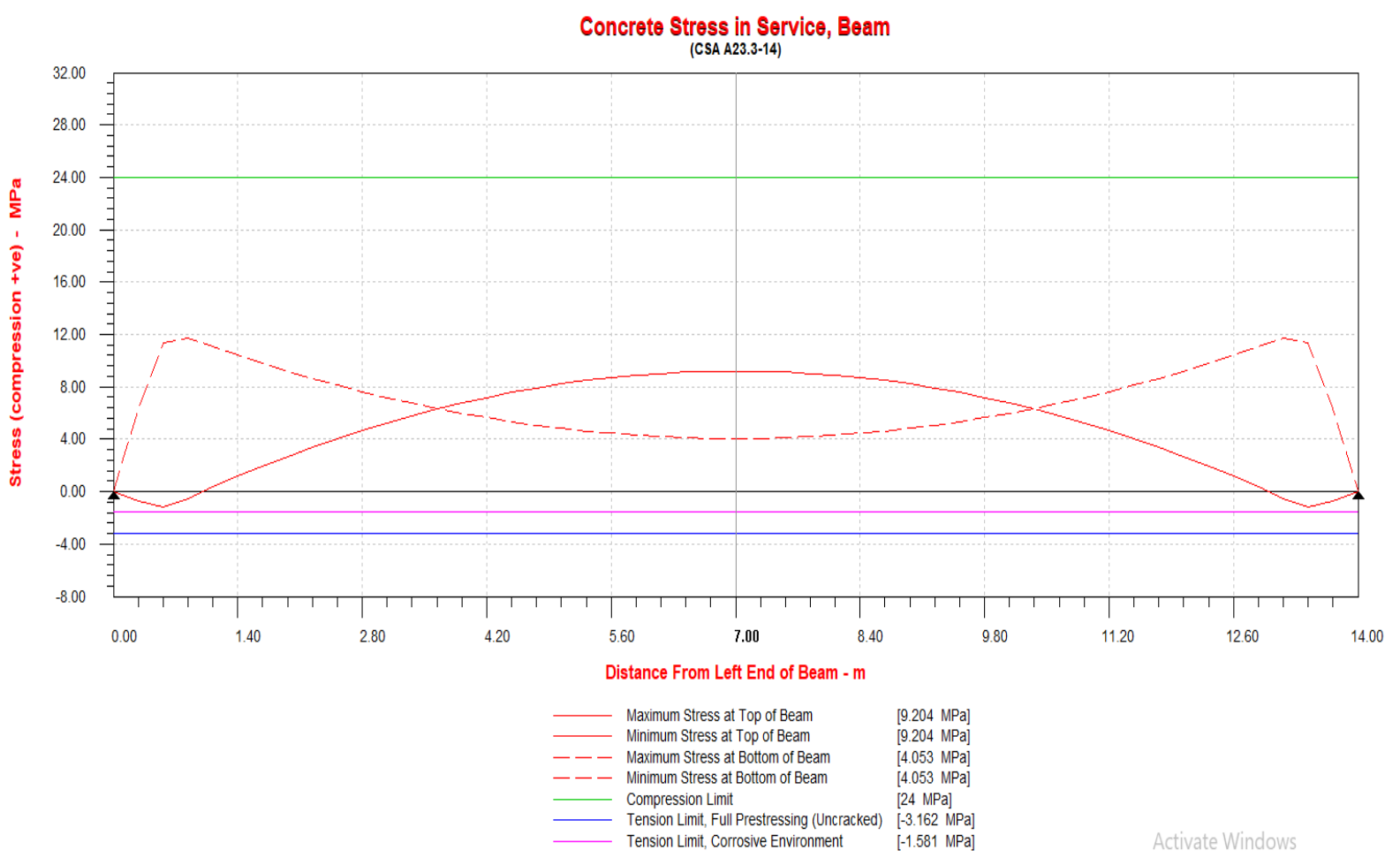

Figure 5: The stress profile for the RC beam for the 10 strand scenario

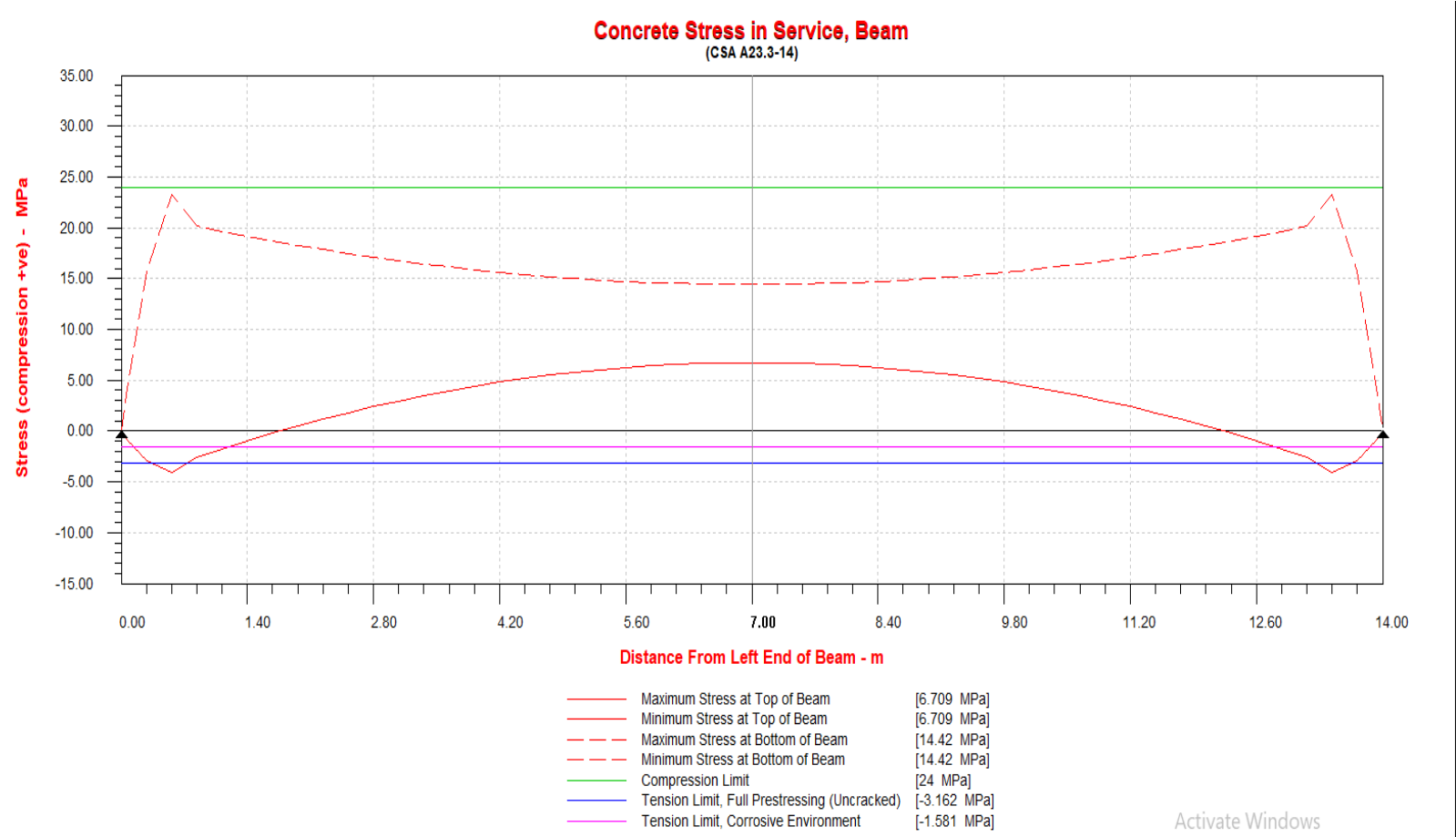

Figure 6: The stress profile for the RC beam for the 20 strand scenario

The specimen in this research were tested using compressive strength on the deflection and cracking properties [1]. The results have shown that external prestressing can be used to rehabilitate RC beams. Further, the results in figure 5 and 6 demonstrate that external prestressing increases the shear strength and the loading capacity of the rehabilitated RC beams. 


\section{Conclusion}

Conclusively, the study has evaluated the application of external prestressing in rehabilitating reinforced concrete beams. The external prestressing techniques strengthened the restored $\mathrm{RC}$ beams by increasing the loading carrying capacity and the shear strength. The results in this evaluation can be used to recommend the future application of external prestressing, especially in urban bridges. The ability to monitor, remove, and replace the structural members in a bridge makes it easy to maintain the structure. It is now evident that external prestressing can be used for rehabilitation of the structures.

\section{References}

[1] A. Demir, E. Ercan and D. D. Demir, "Strengthening of reinforced concrete beams using external steel members," Steel and Composite Structures, vol. 27, no. 4, pp. 453-464, 2018.

[2] H. Kaur and J. Singh, "A Review on External Prestressing in Concrete," International Research Journal of Engineering and Technology, vol. 4, no. 5, pp. 1801-1805, 2017.

[3] R. Muthukumar and N. Balasundaram, "Rehabilitation of Distressed Concrete Beams Using External Prestressing - Experimental Study," International Journal of Applied Engineering Research, vol. 12, no. 15, pp. 4806-4810, 2017.

[4] X. Xue, X. Wang, X. Hua, M. Wu, L. Wu, Z. Ma and J. Zhou, "Experimental Investigation of the Shear Behavior of a Concrete Beam without Web Reinforcements Using External Vertical Prestressing Rebars," Advances in Civil Engineering, vol. 2019, pp. 1-13, 2019.

[5] H. Yue-lin, W. Jong-hwei, Y. Tsong, H. Chien-hsing and L. Yiching, "Strengthening reinforced concrete beams using prestressed glass fiber-reinforced polymer-Part I: Experimental study," Journal of Zhejiang University-SCIENCE A, vol. 6, no. 3, pp. 166-174, 2005.

[6] K. Ganesh and S. K. Sekar, "A Review of Behaviour of Externally Prestressed Beams," International Journal of Civil Engineering and Technology, vol. 9, no. 7, pp. 382-389, 2018.

[7] A. A. Allawi, "Behavior of Strengthened Composite Prestressed Concrete Girders under Static and Repeated Loading," Advances in Civil Engineering, vol. 2017, pp. 1-13, 2017.

[8] I. A. M, "Parametric Study of Continuous Concrete Beam Prestressed with External Tendon," Jordan Journal of Civil Engineering, vol. 4, no. 3, pp. 211-221, 2010.

[9] T. El-Shafiey and A. Atta, "No Access Retrofitting of reinforced concrete beams in shear using external prestressing technique," Magazine of Concrete Research, vol. 64, no. 3, pp. 201-211, 2012.

[10] A. El-HakimKhalil, E. Etman, A. Atta and S. Fayed, "Torsional Strengthening of RC Box Beams Using External Prestressing Technique," IOSR Journal of Mechanical and Civil Engineering, vol. 12, no. 2, pp. 30-41, 2015.

[11] S.-H. Lee, K.-J. Shin and H.-D. Lee, "Post-Tensioning Steel Rod System for Flexural Strengthening in Damaged Reinforced Concrete (RC) Beams," Applied Sciences, vol. 8, no. 10, pp. 1763-1790, 2018.

[12] M. Y. Sabra, Y. A. Temsah, O. M. Baalbaki, and A. Z. Saleh, "Repair of Damaged Prestressed Concrete Beams Using CFRP Fabric and Stitching Techniques," International Journal of Civil Engineering and Technology, vol. 9, no. 10, pp. 427-440, 2018.

[13] Y. Tianlai, T. Shuai, Z. Yunpeng, and Z. Liyuan, "Experimental and Theoretical Investigation of Bending in Concrete Beams Strengthened with External Prestressing CFRP Tendons," The Open Construction \& Building Technology Journal, vol. 10, pp. 492-510, 2019.

[14] A. Madaj and K. Mossor, "Evaluation of External Prestressing as a Strengthening Method for Existing Concrete Bridges," Structural Engineering International, 2019.

[15] S. Aykac, I. Kalkan, B. Aykac, S. Karahan, and S. Kayar, "Strengthening and Repair of Reinforced Concrete Beams Using External Steel Plates," Journal of Structural Engineering, vol. 139, no. 6, 2013.

[16] Rashid, S., Ahmed, A., Barazanchi, I. Al, and Jaaz, Z.A., 2019. Clustering algorithms subjected to Kmean and gaussian mixture model on multidimensional data set. Periodicals of Engineering and Natural Sciences, 7 (2), pp.448-457. 
[17] B. Durakovic, "Design for Additive Manufacturing: Benefits, Trends and Challenges", Periodicals of Engineering and Natural Sciences (PEN), vol. 6, pp. 179-191, 2018.

[18] B. Durakovic, "Design of Experiments Application, Concepts, Examples: State of the Art," Periodicals of Engineering and Natural Scinces, vol. 5, no. 3, p. 421-439, 2017.

[19] B. Durakovic, "Thermal Performances of Glazed Energy Storage Systems with Various Storage Materials: An Experimental study", Sustainable Cities and Society, vol. 45, pp. 422-430, 2019. 